\section{Fruit Quality in Induced Polyploids of Actinidia chinensis}

\author{
Jin-Hu Wu ${ }^{1}$ and A. Ross Ferguson \\ The New Zealand Institute for Plant \& Food Research Ltd, Private Bag \\ 92169, Auckland Mail Centre, Auckland 1142, New Zealand
}

Brian G. Murray

School of Biological Sciences, The University of Auckland, Private Bag 92019, Auckland Mail Centre, Auckland 1142, New Zealand

Alison M. Duffy, Yilin Jia, and Canhong Cheng
The New Zealand Institute for Plant \& Food Research Ltd, Private Bag
92169, Auckland Mail Centre, Auckland 1142, New Zealand

Philip J. Martin

Te Puke Research Centre, The New Zealand Institute for Plant \& Food Research Ltd., RD2, Te Puke, New Zealand

Additional index words. anthocyanins, colchicine, chromosome doubling, dry matter content (DM), fruit firmness, fruit flesh color, kiwifruit, fruit skin thickness, maturity, soluble solids content (SSC), vitamin C

\begin{abstract}
Fruit of colchicine-induced tetraploids of Actinidia chinensis were $50 \%$ to $60 \%$ larger than those of their diploid progenitors. In addition to fruit size, fruit quality is a key issue in any commercialization of these autotetraploids. We have made the first detailed study of the effects of chromosome doubling on fruit quality parameters other than size: these attributes include flesh firmness, color, soluble solid content (SSC), dry matter content (DM), vitamin $\mathrm{C}$ content, fruit skin thickness, and red pigmentation distribution in red-fleshed kiwifruit. Four selections from colchicine-induced tetraploids from the yellow-fleshed kiwifruit cultivar Hort16A were trialed for the stability of their fruit quality. Analysis of fruit at harvest over 3 years showed that fruit of the induced autotetraploids were significantly softer (lower flesh firmness), had lower DM, and had a less intense golden flesh color than fruit of their diploid progenitor. During development, SSC of fruit of the autotetraploid plants started to increase earlier than in the diploid 'Hort16A'. This has been confirmed by replicated trials. No difference was found in vitamin $\mathrm{C}$ content between fruit of autotetraploids and diploids. Autotetraploids had significantly thicker skins than diploid 'Hort16A'. Induced autotetraploids from three female genotypes of red-fleshed $\boldsymbol{A}$. chinensis showed similar trends to autotetraploids of 'Hort16A' in fruit flesh firmness and outer pericarp flesh color, DM, SSC, and vitamin C. All the traits analyzed indicated that fruit of the autotetraploid plants matured earlier than those of their diploid progenitors. Furthermore, red pigmentation, one of the most important traits for red-fleshed kiwifruit breeding, showed a reduction in both intensity and distribution in the autotetraploids compared with their diploid progenitors. There was considerable variation among fruit of autotetraploid plants regenerated from each diploid progenitor. Therefore, selection among the regenerants may be required to achieve the best outcome after ploidy manipulation in kiwifruit breeding.
\end{abstract}

Chromosome doubling has been widely explored as a bridge to help gene introgression between different ploidy levels both between and within species for crop

Received for publication 23 Jan. 2013. Accepted for publication 11 Apr. 2013.

We thank Nihal de Silva for statistical advice and Ian Hallett for guidance on measurements of skin thickness; Robert Campin, Paul Datson, Meng Meng, Eric $\mathrm{Wu}$, and Hao Wu for assistance with fruit analysis and collection of some data; Tony Corbett for figure design; Jem Burdon, Jinquan Feng, and Anne Gunson for critical comments on the manuscript; and Mike Currie, Pauline Mooney. and Alan Seal for useful discussions.

${ }^{1}$ To whom reprint requests should be addressed; e-mail jinhu.wu@plantandfood.co.nz.
Fruit quality in kiwifruit has many components such as fruit size, shape, flesh texture, color, flavor, firmness, DM, SSC, vitamin C content, core size, and skin color and thickness. Further expansion of the kiwifruit industry will require the development of new cultivars with enhanced sweetness, flavor, and storage life and a variety of flesh colors (Ferguson and Seal, 2008) as well as optimum fruit quality with easy handling during field management and harvesting, packing, storage, and marketing.

In this article, we compare some aspects of fruit quality in some diploid selections of Actinidia chinensis with those of fruit from autotetraploids produced by colchicineinduced chromosome doubling. Our aim was to determine the effects of increasing the number of genomes on fruit quality and development using a number of easily measured attributes. During fruit development, SSC at harvest is an indicator of fruit maturity, and DM content reflects the potential SSC at eating ripeness once starch reserves have been converted to sugar (Burdon et al., 2004; Feng et al., 2011). Flesh firmness can also be used to assess fruit maturity and storage ability. One of the selections studied was 'Hort16A' and autotetraploids derived from it. As fruit of 'Hort16A' mature, the flesh color changes from green to yellow, and flesh hue angle $\left(h^{\circ}\right)$ is one of the key parameters used to determine the quality and maturity of its fruit because the color appeals greatly to consumers. The three other selections studied came from a program to develop kiwifruit with red flesh: the extent and intensity of red pigmentation are important parameters for assessing quality in these selections. These various quality attributes were used to assess the possible commercial potential of the different selections and the autotetraploid plants derived from them.

\section{Materials and Methods}

Plants. The plants used comprised 11 clonally propagated vines of the diploid $A$. chinensis cultivar Hort16A and 77 independently derived colchicine-induced tetraploid regenerants of this cultivar. There were 11 clonally propagated plants of three genotypes of $A$. chinensis with red flesh, 'Hort22D', Selection 1 and Selection 2 (Wu et al., 2012), and 88 independently derived colchicine-induced autotetraploid plants produced from these three genotypes. Autotetraploids of 'Hort16A' were grouped into Type A (55 regenerants with large fruit of the same general shape as those of their diploid progenitor, 'Hort16A') and Type B (22 regenerants with smaller "fasciated" fruit); no such variation was observed in the autotetraploid plants regenerated from the three diploid red-fleshed genotypes of $A$. chinensis (Wu et al., 2012). All the regenerated autotetraploids were grown from in vitro culture and were on their own roots.

The plants of 'Hort16A' and the 77 tetraploid regenerants were planted in the Plant \& Food Research Orchard at Kerikeri. Two different genotypes of tetraploid $A$. chinensis 
males from the Plant \& Food Research germplasm collection and a diploid $A$. chinensis male cultivar (Meteor) (1:2) were planted at a ratio of one male:eight female plants.

The three "red-fleshed" genotypes and their autotetraploids were planted in the Plant \& Food Research Orchard at Te Puke. The diploid male ('Meteor') was planted at a ratio of one male:six females along the same row.

The tetraploid plants with their clonally propagated progenitor plants as controls, and males as pollenizers, were planted randomly in the rows of the two orchards as described by $\mathrm{Wu}$ et al. (2012). All vines were managed following standard orchard practices and grown on a modified T-bar structure.

Fruit quality attributes. Fruit quality was evaluated on a sample of 10 fruit/year (200608 ) that had been used to measure individual fruit weights and dimensions as described previously by $\mathrm{Wu}$ et al. (2012). Measurements began in the third year after planting in the orchard. Fruit were harvested on 23 May in 2006, 5 Apr. in 2007, and 11 May in 2008. The method of sampling was described previously (Wu et al., 2012). Fruit quality was evaluated over three seasons (2006-08) for diploid 'Hort16A' and its autotetraploid regenerants and two or three seasons (2007, 2008, and 2009) for the three diploid redfleshed genotypes and their autotetraploid regenerants. Fruit attributes other than fruit weight and dimensions were evaluated as follows:

Flesh firmness was measured, using a handheld penetrometer (EFFEGI, Alphonsine, Italy; 8-mm probe), at opposite sides at the equator of the fruit after removal of a 1-mm layer of skin and outer pericarp. The two readings were averaged (Feng et al., 2003).

Flesh color in the outer pericarp was measured at opposite sides at the equator of each fruit using a Minolta CR-300 Chroma meter (Osaka, Japan) after removal of a 2-mm layer of skin and outer pericarp. The two readings were averaged and color was expressed as hue angle $\left(h^{\circ}\right)$, chroma $\left(\mathrm{C}^{*}\right)$, and lightness $\left(\mathrm{L}^{*}\right)$ (Feng et al., 2003).

Soluble solids content was measured using a handheld refractometer (Atago ${ }^{\circledR}$, Tokyo, Japan) with one drop of juice from each end of the fruit combined.

Dry matter content was measured by weighing a 4-mm thick equatorial slice of fruit cross-section (including skin, flesh, seeds. and core tissue) before and after drying at $60{ }^{\circ} \mathrm{C}$ for $24 \mathrm{~h}$.

Vitamin $C$ (ascorbic acid) was measured by the method described by Ferguson and MacRae (1992) using three batches of 15 fruit from each plant. A composite sample from each batch of $\approx 300 \mathrm{~g}$ was prepared by taking a sector, approximately onesixth, from each fruit. The reduced ascorbic acid of the samples was measured by titration against 2,6-dichlorophenolindophenol (Deutsch, 1996).
Skin thickness was measured by taking a section of the skin using a Vibratome sectioning system (Series 1000, USA), photographing with a digital camera attached to an Olympus microscope (VanoxAHBT3), and determining skin thickness using an ImageJ system (image process and analysis in Java).

Pigmentation in red-fleshed A. chinensis. The intensity of red pigmentation was scored on a 0 to 5 scale with no red scored as 0 and scores 1 to 5 (right to left, Fig. 1) representing a slight tinge of red, pale pink or red color, distinct red, dark red, and intense red, respectively, in equatorial cross-sections (Cheng et al., 2007). Pigment distribution was scored separately in fruit cross and longitudinal sections. The transverse distribution was scored by taking an equatorial cross-section of the fruit and recording the extent to which red pigments were distributed radially from the outside of the core to the skin using a score of 0 to 10 based on $10 \%$ increments of the radial length. The longitudinal distribution was scored by recording the extent to which red pigmentation extended from the stalk end to the stylar end based on $10 \%$ increments of the locule length (Fig. 2).

Trial of grafted colchicine-induced autotetraploid regenerants Type A from 'Hort 16A'. Based on observations of fruit size and shape from 2005 to 2007 , four colchicine-induced autotetraploid Type A plants (RG1, RG2, RG3, and RG4) were selected from the Type A regenerants for a trial to test genetic stability. Bud wood of the selected Type A plants and their diploid progenitor 'Hort16A' was grafted onto 2year-old 'Bruno' seedling rootstocks at the Plant \& Food Research Orchard, Te Puke, in
2007. Four grafted plants of each were placed at random at a spacing of $5 \times 3 \mathrm{~m}$ with 'Sparkler', 'Meteor', and 'Bruce' (all diploid) in equal proportions as pollenizers planted at a ratio of one male:five females. Harvest data were collected in 2011 and average fruit weights from each vine were given in Wu et al. (2012). Fruit were sampled from each plant for evaluation of fruit quality over the 2 months before full harvest.

Data analysis. Statistical Analysis System (SAS Institute Inc., 2000-04) was used for the pairwise $t$ tests (Fisher's least significant difference tests) following Wu et al. (2012) to examine the differences between the autotetraploids and their diploid progenitors in the same year or the differences between years for the autotetraploids or their diploid progenitors.

\section{Results}

\section{Fruit flesh firmness}

'Hort16A'. Fruit of induced autotetraploid regenerants of 'Hort 16A' varied in flesh firmness. Data from three consecutive harvests showed that firmness varied by year (because of different harvest dates), vine, regenerant, and fruit type (Fig. 3). Fruit of induced autotetraploid Type B plants were significantly softer than fruit of Type A plants in 2007 and 2008, but no difference was detected in 2006; fruit of both Type A and Type B autotetraploids were softer than those of their progenitor, diploid 'Hort16A', at each harvest date (Table 1). This trend was consistent over years.

Fruit from the replicated trial of four different autotetraploid Type A regenerants were also softer than those of their progenitor, diploid 'Hort16A', at all sampling times. Firmness measured at different sampling dates indicated that the fruit from autotetraploids

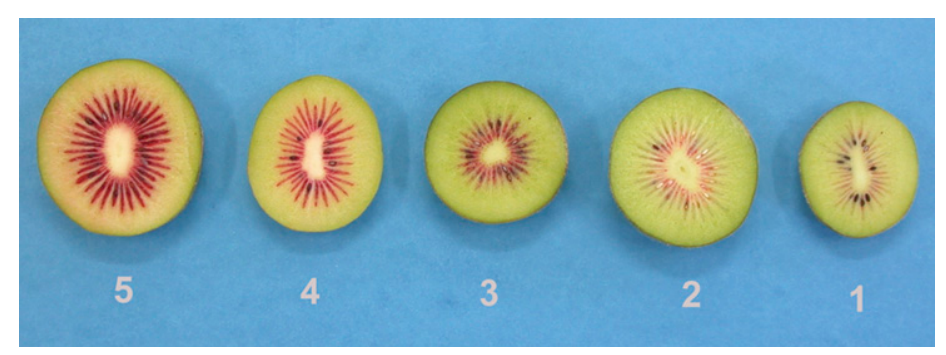

Fig. 1. Score of the intensity of red pigmentation in equatorial cross sections of red-fleshed Actinidia chinensis fruit.
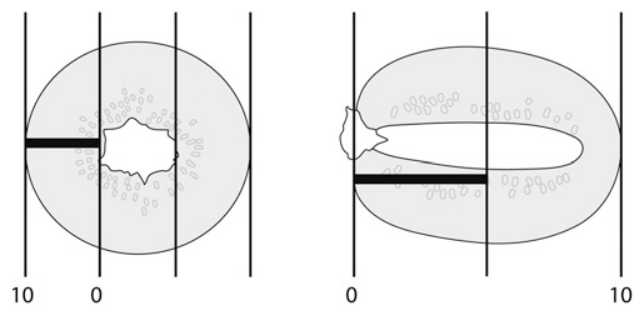

Fig. 2. Score of cross-sectional (left) and longitudinal (right) distribution of red pigments in Actinidia chinensis fruit. 

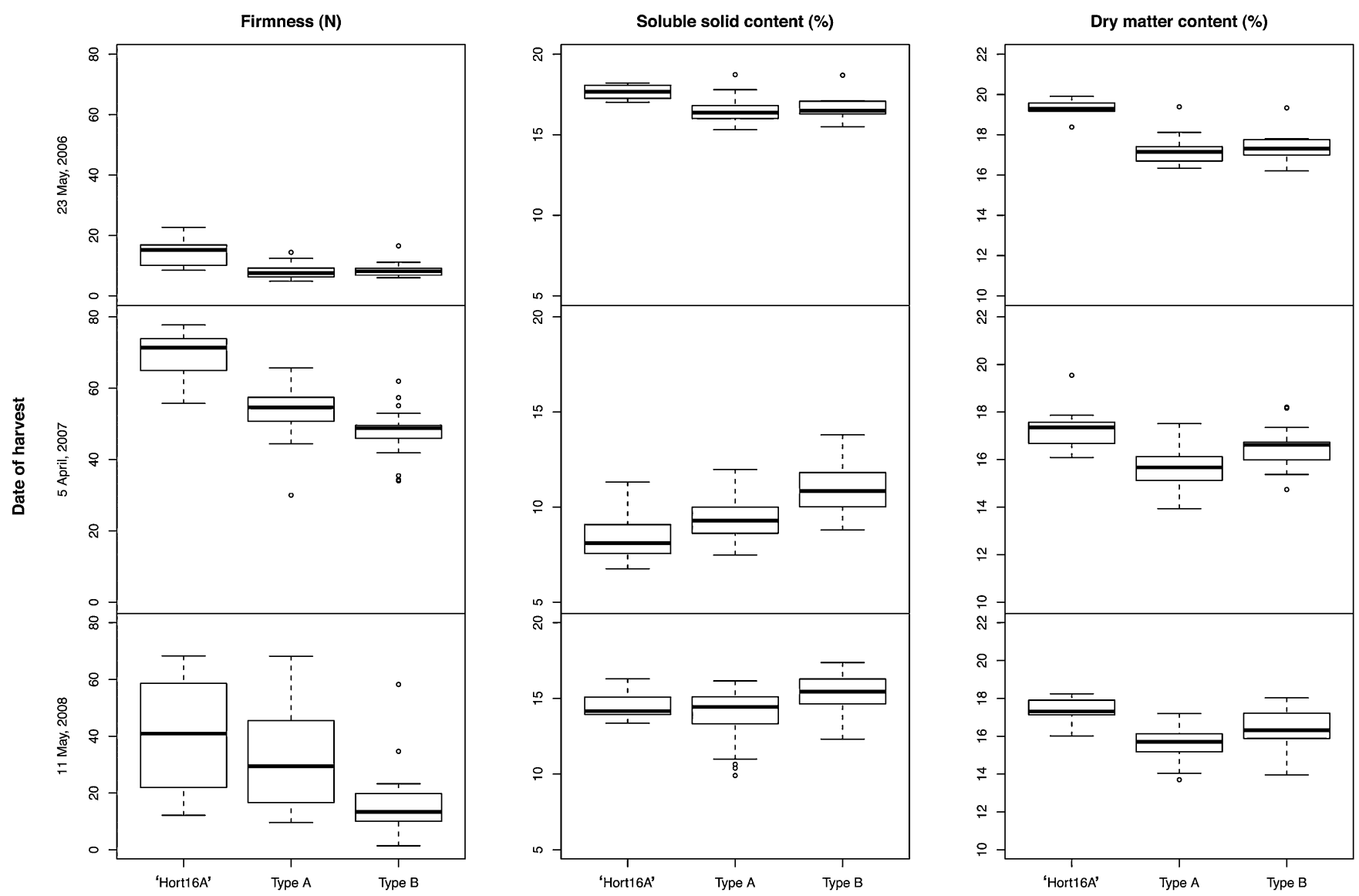

Fig. 3. Boxplots of vine means during 2006-08 for fruit flesh firmness, soluble solids content, and dry matter content of diploid Actinidia chinensis 'Hort16A' and the autotetraploids induced from it by colchicine. In box plots, the upper and lower edges of the box represent the 75th and 25th percentiles, respectively, and the median is represented by the bold horizontal line. The whiskers extend to 1.5 times the interquartile range (i.e., the distance between the 25 th and 75 th percentiles) or the minimum or maximum, whichever is more extreme. Any observations beyond the whiskers are shown by the plot symbol and are considered as outliers.

Table 1. Fruit flesh firmness, soluble solids content, and dry matter content of diploid Actinidia chinensis 'Hort16A' and regenerated plants of colchicine-induced autotetraploids derived from it. ${ }^{2}$

\begin{tabular}{|c|c|c|c|c|c|c|c|c|c|c|}
\hline \multirow[b]{2}{*}{ Group } & \multirow[b]{2}{*}{ Ploidy } & \multicolumn{3}{|c|}{ Fruit flesh firmness $(\mathrm{N})$} & \multicolumn{3}{|c|}{ Soluble solids content ( ${ }^{\circ}$ Brix $)$} & \multicolumn{3}{|c|}{ Dry matter content $(\%)$} \\
\hline & & 2006 & 2007 & 2008 & 2006 & 2007 & 2008 & 2006 & 2007 & 2008 \\
\hline Type A & $4 x$ & $7.8 \pm 0.4 \mathrm{~b}$ & $53.9 \pm 1.0 \mathrm{~b}$ & $32.4 \pm 2.0 \mathrm{a}$ & $16.5 \pm 0.1 \mathrm{~b}$ & $9.4 \pm 0.1 \mathrm{~b}$ & $14.0 \pm 0.2 \mathrm{c}$ & $17.2 \pm 0.1 \mathrm{~b}$ & $15.6 \pm 0.1 \mathrm{c}$ & $15.6 \pm 0.1 \mathrm{c}$ \\
\hline
\end{tabular}

${ }^{z}$ Ten-fruit samples taken from each vine during 2006-08. All data are averages \pm SES.

${ }^{\mathrm{y}}$ Values followed by different letters within the same column for the same item in the same year are significantly different $(P<0.01)$.

began to mature earlier than those of 'Hort16A' (Fig. 4A).

Red-fleshed genotypes. Fruit of induced autotetraploids were much softer; flesh firmness was $\approx 50$ to $60 \mathrm{~N}$ lower than that of fruit of their diploid progenitors in all three genotypes analyzed from the 2009 evaluation (Table 2). However, these differences, although dramatic, are for only one season.

\section{Flesh color}

'Hort 16A'. The differences in outer pericarp flesh color were similar to those found in fruit firmness: 'Hort16A' had significantly higher fruit flesh color reading values than the autotetraploids induced from it $(P<0.01)$ (Table 3) (with the exception of hue angle in 2008).

Significant differences in fruit flesh color of the outer pericarp between years were detected, but the relative differences between the diploids and tetraploids were maintained. Variation in outer pericarp flesh color was also observed among induced autotetraploid regenerants and vines of diploid 'Hort16A' (data not shown).

Flesh color reading values, e.g., hue angle $\left(h^{\circ}\right)$, from fruit of the replicated trial of four selected autotetraploid Type A regenerants of 'Hort16A' also showed similar trends in that they were lower than in their progenitor 'Hort16A' during the study (Fig. 4B-D).

Red-fleshed genotypes. Similar results were found for the genotypes that had red pigmentation in the inner pericarp. Each year, significantly higher values for lightness and chroma for outer pericarp flesh (yellow) were recorded for all three diploid genotypes of red-fleshed $A$. chinensis than for the corresponding induced autotetraploids. The one exception was that in 2009 , the value for lightness of Selection 2 was not significantly higher. Hue angle varied with year and with genotype (Table 4).

In all 3 years, the intensity of the fruit red pigmentation in the inner pericarp was significantly greater in diploids of 'Hort22D' than in autotetraploids induced from it $(P<$ 0.05 ) (Table 4). Mixed results were obtained for the other genotypes. There was considerable variation in fruit pigmentation among fruit of autotetraploid regenerants derived from the same diploid progenitor. Some autotetraploids had deeper red pigmentation in the cross-section than the diploid progenitor.

\section{Soluble solids content}

'Hort 16A'. Generally, Type B autotetraploid fruit had significantly higher SSC at harvest than fruit of Type A or of the diploid progenitor (Table 1). SSC varied with vine 

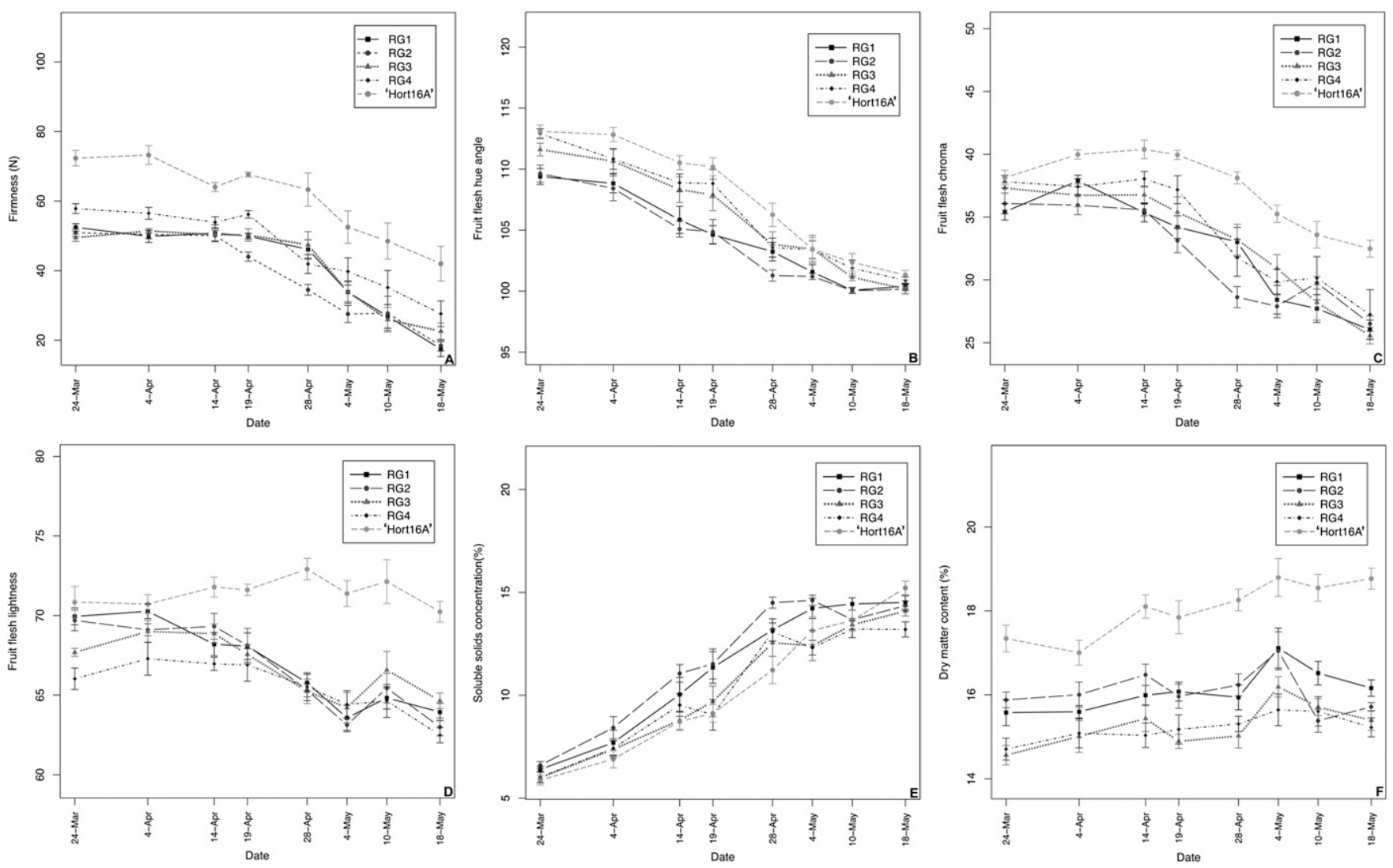

Fig. 4. (A-F) Trends during the 2 months before harvest, 2011, in fruit firmness, outer pericarp flesh hue angle $\left(h^{\circ}\right)$, chroma, and lightness, soluble solids content, and dry matter content of Actinidia chinensis 'Hort16A' and four autotetraploid Type A regenerants induced from it by colchicine.

Table 2. Fruit flesh firmness, soluble solids content, and dry matter content of three diploid genotypes of red-fleshed Actinidia chinensis and of autotetraploids induced from them by colchicine. ${ }^{\mathrm{Z}}$

\begin{tabular}{|c|c|c|c|c|c|c|c|}
\hline \multirow[b]{2}{*}{ Genotype } & \multirow[b]{2}{*}{ Ploidy } & \multirow{2}{*}{$\begin{array}{l}\text { Fruit flesh firmness (N) } \\
2009\end{array}$} & \multicolumn{3}{|c|}{ Soluble solids content ( ${ }^{\circ}$ Brix $)$} & \multicolumn{2}{|c|}{ Dry matter content $(\%)$} \\
\hline & & & 2007 & 2008 & 2009 & 2007 & 2009 \\
\hline Hort22D & $4 x$ & $27.5 \pm 3.9 \mathrm{~b}$ & $11.7 \pm 1.1 \mathrm{a}$ & $15.9 \pm 0.3 \mathrm{a}$ & $14.7 \pm 0.3 b$ & $18.8 \pm 0.4 \mathrm{~b}$ & $17.8 \pm 0.3 \mathrm{~b}$ \\
\hline Selection 2 & $2 x$ & $67.7 \pm 0 \mathrm{a}$ & $14.4 \pm 2.1 \mathrm{~b}$ & $-^{\mathrm{x}}$ & $15.7 \pm 0 \mathrm{a}$ & $22.4 \pm 0.4 \mathrm{a}$ & $18.1 \pm 0 \mathrm{a}$ \\
\hline Selection 2 & $4 x$ & $14.7 \pm 2.9 \mathrm{~b}$ & $16.7 \pm 3.2 \mathrm{a}$ & $16.7 \pm 0.8$ & $14.7 \pm 0.3 b$ & $20.6 \pm 0.8 \mathrm{~b}$ & $17.1 \pm 0.3 \mathrm{a}$ \\
\hline
\end{tabular}

${ }^{\mathrm{z}}$ All data are averages \pm SEs.

${ }^{y}$ Values followed by different letters within the same column for the same item of the same genotype in the same year are significantly different; for fresh firmness, the significant difference at $P<0.01$; for soluble solid content and dry matter content, the significant difference at $P<0.05$.

'Insufficient fruit.

Table 3. Outer pericarp flesh color: hue angle $\left(h^{\circ}\right)$, chroma $\left(C^{*}\right)$, and lightness $\left(L^{*}\right)$ of fruit from vines of diploid Actinidia chinensis 'Hort16A' and regenerated plants of colchicine-induced autotetraploids derived from it. ${ }^{\mathrm{z}}$

\begin{tabular}{|c|c|c|c|c|c|c|c|c|c|c|}
\hline \multirow{2}{*}{ Group } & \multirow{2}{*}{ Ploidy } & \multicolumn{9}{|c|}{ Outer pericarp flesh color } \\
\hline & & \multicolumn{3}{|c|}{ Hue angle $\left(h^{\circ}\right)$} & \multicolumn{3}{|c|}{ Chroma $\left(C^{*}\right)$} & \multicolumn{3}{|c|}{ Lightness $\left(L^{*}\right)$} \\
\hline Hort16A & $2 x$ & $99.3 \pm 0.1 \mathrm{a}^{y}$ & $105.0 \pm 0.6 \mathrm{a}$ & $102.6 \pm 0.3 \mathrm{ab}$ & $31.6 \pm 0.3 \mathrm{a}$ & $37.3 \pm 0.5 \mathrm{a}$ & $32.0 \pm 1.0 \mathrm{a}$ & $67.1 \pm 0.1 \mathrm{a}$ & $75.6 \pm 0.6 \mathrm{a}$ & $69.3 \pm 1.0 \mathrm{a}$ \\
\hline Type B & $4 x$ & $98.2 \pm 0.4 \mathrm{ab}$ & $102.2 \pm 0.4 b$ & $101.3 \pm 0.4 b$ & $27.5 \pm 0.7 \mathrm{~b}$ & $35.7 \pm 0.5 b$ & $27.7 \pm 0.6 \mathrm{~b}$ & $58.0 \pm 0.6 \mathrm{c}$ & $70.8 \pm 0.4 \mathrm{c}$ & $60.7 \pm 0.8 c$ \\
\hline
\end{tabular}

${ }^{\mathrm{z}}$ Ten-fruit samples were taken from each vine during 2006-08. All data are averages \pm SES.

${ }^{y}$ Values followed by different letters within the same column for the same year are significantly different $(P<0.01)$.

and regenerants among the three genotypes and also with year over the 3 years among the three groups (Fig. 3).

Fruit from the replicated trial of four autotetraploid Type A regenerants showed the same trends in SSC as fruit of their diploid progenitor, 'Hort16A', except that all fruit from autotetraploids initially had a higher SSC and a greater rate of increase in SSC than fruit of their diploid progenitor, 'Hort16A' (before 4 May). Eventually the SSC values of fruit of the diploid were as high (or even higher) as those of fruit of the autotetraploids (Fig. 4E).
Red-fleshed genotypes. Fruit of the autotetraploids had lower SSC than fruit of the corresponding diploids (Table 2). There was one exception: fruit of induced autotetraploids of Selection 2 had significantly higher SSC than those of the diploid progenitor $(P<0.05)$ (Table 2). Average SSC varied between years. 


\section{Dry matter content}

'Hort16A'. Fruit of diploid 'Hort16A' had the highest DM, autotetraploid Type A fruit had the lowest DM in all 4 years of the study, and Type B fruit had intermediate values (Table 1). Fruit in the replicated trial of the four autotetraploid Type A regenerants gave similar results; at all sampling times, they all had lower DM than did fruit of the diploid progenitor 'Hort 16A' (Fig. 4F).

Variation in fruit DM between years from 2006 to 2008 was observed among the three groups, the variation of fruit DM from all three groups of fruit having the same trend among the 3 years. Only in 2006 was DM significantly higher than in the other two seasons $(P<0.01)$; no significant differences were found between the other two seasons.

Variation was also observed between vines or regenerants within the same group in any one year (Fig. 3). In 3 years' observation with subsamples from all vines or regenerants, DM of 'Hort16A' fruit was $16.0 \%$ to $19.5 \%$, of Type B fruit $13.3 \%$ to $19.3 \%$, and of Type A fruit $12.4 \%$ to $18.3 \%$.

Red-fleshed genotypes. In both years, fruit of the induced autotetraploids had lower DM than did fruit of the respective diploid progenitors. The difference between the two ploidy levels varied with the genotype (Table 2). DM also varied between years.

\section{Vitamin $\mathbf{C}$ content}

'Hort 16A'. Fruit of the original diploid 'Hort16A' and of the Type A and Type B autotetraploids all contained 100 to $120 \mathrm{mg}$ vitamin $\mathrm{C} / 100 \mathrm{~g}$ fresh weight irrespective of ploidy. The differences observed in vitamin $\mathrm{C}$ content (although higher in autotetraploids) were not statistically significant.

Red-fleshed genotypes. Differences in fruit vitamin $\mathrm{C}$ content between the original diploids and induced autotetraploid were not statistically significant. Differences in fruit vitamin $\mathrm{C}$ content of the different diploid genotypes were paralleled in the autotetraploids induced from those diploids: the diploid with the highest vitamin $\mathrm{C}$ concentrations produced autotetraploids with the highest concentrations. Similarly, the diploid progenitor with the lowest vitamin $\mathrm{C}$ produced autotetraploids with the lowest concentrations (Table 5).

\section{Skin thickness of 'Hort16A'}

All fruit of induced autotetraploids from 'Hort16A' had brown skins at harvest, whereas fruit of the diploid progenitor vines often had greenish skins. Such differences in color may be attributable, at least in part, to differences in canopy development and hence exposure of the fruit to light. However, fruit skins of the autotetraploids were also significantly thicker than those of the fruit of the diploid progenitor (Table 6). Type B autotetraploid fruit had the thickest skins.

\section{Discussion}

Inducing a doubling of the ploidy of the diploid kiwifruit selections we studied significantly increased fruit size: fruit of the colchicine-induced autotetraploids were, on average, $50 \%$ to $60 \%$ bigger than those of their diploid kiwifruit progenitors (Wu et al., 2012). Some spontaneously occurring budsports of 'Hort16A' also have fruit twice the average size of 'Hort16A' fruit (Martin, 2005). A number of these budsports have since been shown by flow cytometry to be tetraploid or mixoploid (diploid + tetraploid) (Ferguson et al., 2009). Increasing the ploidy, either spontaneously or by manipulation, can therefore increase fruit size in some kiwifruit selections. However, fruit size is only one attribute of fruit quality, and many other quality attributes will be important in determining whether the colchicine-induced autotetraploids can be used commercially.

An increase in fruit size was often accompanied by changes in fruit shape (Wu et al., 2012). The colchicine-induced autoploid regenerants from 'Hort16A' could be divided into two classes, Type A and Type B, on fruit shape. Type B fruit would not be acceptable commercially because of their shape.

Fruit of the colchicine-induced autotetraploids had lower fruit flesh firmness and lower

Table 5. Vitamin C content in 2008 of fruit of three diploid genotypes of red-fleshed Actinidia chinensis and the autotetraploids induced from them by colchicine. ${ }^{z}$

\begin{tabular}{lccc}
\hline Genotype & Ploidy & $\begin{array}{c}\text { Number of vines } \\
\text { or regenerants }\end{array}$ & $\begin{array}{c}\text { Vitamin C (mg/100 g } \\
\text { fresh weight) }\end{array}$ \\
\hline Hort22D & $2 x$ & 4 & $147.9 \pm 8.2$ \\
Hort22D & $4 x$ & 4 & $156.3 \pm 9.4$ \\
Selection 1 & $2 x$ & 4 & $121.6 \pm 5.2$ \\
Selection 1 & $4 x$ & 3 & $114.9 \pm 4.3$ \\
Selection 2 & $2 x$ & 1 & 112.9 \\
Selection 2 & $4 x$ & 4 & $117.8 \pm 6.7$ \\
\hline
\end{tabular}

${ }^{\mathrm{z}}$ All data are averages \pm SES.

Table 6. Fruit skin thickness measured in 2007 of diploid Actinidia chinensis 'Hort16A' and the autotetraploids induced from it by colchicine. ${ }^{2}$

\begin{tabular}{lccc}
\hline Group & Ploidy & Vines sampled & Skin thickness $(\mathrm{mm})$ \\
\hline Hort16A & $2 x$ & 2 & $0.026 \pm 0.001 \mathrm{c}^{\mathrm{y}}$ \\
Type A & $4 x$ & 6 & $0.039 \pm 0.001 \mathrm{~b}$ \\
Type B & $4 x$ & 2 & $0.046 \pm 0.001 \mathrm{a}$ \\
\hline
\end{tabular}

${ }^{\mathrm{z}}$ All data are averages \pm SES.

${ }^{y}$ Values followed by different letters are significantly different $(P<0.01)$. 
DM than fruit of their diploid progenitors. There was some variation in these characteristics from year to year because fruit were harvested at different maturity in different years but the trends in variation were the same for both autotetraploids and their progenitors. Fruit of Type B autotetraploid had the highest $\mathrm{SSC}$, but the difference in SSC between Type $A$ and 'Hort16A' fruit varied with year during the 3 -year analysis. These variations with year make it difficult to draw firm conclusions. The variation between years in fruit firmness and SSC was largely the result of the fruit being harvested at different maturities each year. The differences and variation in DM, SSC, and flesh color between 'Hort16A' (diploid) and their induced tetraploids were confirmed by a trial of selected four large-fruited regenerants (with Type A fruit). In that trial, the trends were consistent and revealed a change in fruit texture. Unfortunately, data for only 1 year are available, because many of the plants in the trial have since been lost to bacterial canker of kiwifruit (caused by Pseudomonas syringae pv. actinidiae). Likewise, many of the original induced autotetraploid plants of the red-fleshed genotypes have since died.

A preliminary report described how fruit of spontaneous large-fruited budsports of 'Hort16A' likewise had lower flesh firmness, lower DM, and lower SSC than fruit of the normal diploid 'Hort16A' (Martin, 2005).

Increasing ploidy had no effect on the fruit vitamin $\mathrm{C}$ concentrations in the kiwifruit selections we studied. Although tetraploids contained slightly higher vitamin $\mathrm{C}$ concentrations than their diploid progenitors, the differences were not significant. Differences among the three red-fleshed autotetraploid genotypes in vitamin $\mathrm{C}$ concentrations therefore reflected the differences among the diploid progenitors. In some other crops, increases in ploidy have resulted in higher concentrations of vitamin C. In watermelons, doubling the ploidy of nine different cultivars consistently resulted in an increase in vitamin C (Cheng et al., 2008) and similar results were obtained with eggplant (Li et al., 2002), and Ullucus (Viehmannová et al., 2012). Chromosome doubling might therefore be a useful tool for improving the antioxidant properties of some crops, but apparently not in kiwifruit.

The reduction in fruit DM on doubling the ploidy is particularly important. This is not simply an effect of fruit size: when large numbers of 'Hayward' kiwifruit were graded for size before export, there was no correlation between fruit size and fruit DM (Woodward and Clearwater, 2008).

Lower DM will mean fruit flavor is likely to be poor after storage (Harker et al., 2009). Fruit that are low in DM will inevitably be lower in SSC when ripe (Burdon et al., 2004): because fruit of the autotetraploids were lower in DM than their diploid progenitors, they can be expected to be lower in SSC when ripe. DM has been proposed as an indicator of maturity (and harvest time) and is used to determine returns to kiwifruit orchardists in New Zealand (Burdon et al., 2004; Jaeger et al., 2011). ZESPRI Group Limited (the main exporter of kiwifruit from New Zealand) believes that to maintain its international competitive advantage, and hence higher returns to growers, it needs the fruit it exports to be consistently of higher DM content to ensure that customers receive the fruit they expect with enhanced sweetness, flavor, and storage life (Belrose, Inc., 2009; Jaeger et al., 2011). Thus, although the increased size of the fruit of autotetraploids could provide a commercial advantage, the lower DM would be a real disadvantage. Commercial priorities will determine the relative importance placed on size and flavor in the market acceptance of new cultivars.

SSC of fruit of four selected autotetraploids increased faster than that of 'Hort 16A' early in the season, although later on the values were the same or even lower than that of 'Hort16A'. The initial faster increase could be the result of the fruit of the autotetraploid maturing earlier than fruit of the corresponding diploids. The reduced firmness and the earlier changes in SSC imply that the fruit of autotetraploids do mature earlier than fruit of the diploid progenitors. This conclusion is consistent with studies in other crops: in the grape cultivar Muscat Hamburg, fruit of the autotetraploid were larger and ripened $10 \mathrm{~d}$ earlier than those of diploid plants (Luo et al., 1997); autotetraploid eggplants showed a similar trend in ripening earlier (Li et al., 2002).

The reduction in fruit firmness and DM could be the result of the fruit of autotetraploids having larger cells with larger intercellular spaces; perceived flesh texture could likewise be affected. Polyploids generally have larger cells than their diploid progenitors, as shown by the increased size of their stomata (Van Laere et al., 2011). In ryegrass, such increase in cell size has been shown to be the result of greater elongation rates (Sugiyama, 2005); this fast growth of autotetraploids results in production of the less biomass and lower DM. Ploidy manipulation in other plants often has the same result. In Ullucus, starch content and DM in the microtubers decreased with increased ploidy (Viehmannová et al., 2012), and in Spathiphyllum wallisii, biomass production of tetraploids was less than that of their diploid progenitors (Van Laere et al., 2011). In other cases, however, doubling the chromosome number tended to improve fruit quality, because autotetraploids had higher SSC, sugar content, or other indicators of quality than the diploids, e.g., autotetraploid 'Royal Gala' apple (Liu et al., 2006), autotetraploid 'Meiwa' kumquat (Nukaya et al., 2009), and autotetraploid eggplant ( $\mathrm{Li}$ et al., 2002). These apparently contrasting effects are not really contradictory; different attributes of fruit quality were assessed, e.g., texture (flesh firmness), DM, $\mathrm{SSC}$, and/or sugars; furthermore, the various fruits studied are also very different in structure to kiwifruit and generalizations should be avoided. It is also possible that some of the effects we observed are the result of our comparing plants that had arisen from micropropagation with those resulting from vegetative propagation. Fruit from 'Hayward' kiwifruit plants raised by micropropagation had lower DM than fruit from plants vegetatively propagated by cuttings, but no differences were found in firmness and SSC (Monastra and Testoni, 1992). Further work on fruit structure, physiology, and biochemistry could help us to explain these results and further to explain the effects of ploidy levels on flesh texture and composition.

The color of the fruit flesh of 'Hort16A' and other yellow- or green-fleshed kiwifruit is determined by the relative amounts of chlorophyll and carotenoids (McGhie and Ainge, 2002). As fruit of 'Hort16A' and many other $A$. chinensis selections mature, chlorophyll is lost and the pericarp changes from an initial light green to light yellow (Montefiori et al., 2009) as shown by a reduction in hue angle. A hue angle of $103^{\circ}$ is one of the main indicators that 'Hort16A' fruit in commercial orchards have reached harvest maturity (Minchin et al., 2003). The fruit used in our studies were harvested later in the season than is usual in commercial orchards, but outer pericarp color measurements, especially of hue angle, indicated that fruit of the autotetraploids derived from 'Hort16A' mature earlier than that those of their progenitor, diploid 'Hort16A'. This conclusion is consistent with measurements of their fruit flesh firmness and SSC.

In the red-fleshed selections studied, red pigmentation is largely restricted to the inner pericarp and the decrease in hue angle because the outer pericarp changes from green to yellow can likewise be used as an indicator of harvest maturity. Again it seems that fruit of the autotetraploids might be maturing earlier than those of their diploid progenitors.

If autotetraploid kiwifruit consistently mature earlier, increasing the ploidy could be an interesting way of inducing earlier maturity and fruit harvest, possibly extending the harvest and marketing periods and avoiding the risk of fall frosts. However, to be commercially useful, there would need to be at least several weeks' advance in maturity dates and in our experiments, this seems unlikely with these induced tetraploid kiwifruit.

Fruit of autotetraploid 'Hort16A' have significantly thicker skins than do fruit of diploid 'Hort16A'. This could be a real advantage, because many otherwise promising diploid selections of $A$. chinensis, especially red-fleshed selections, have very thin skins, which make them very susceptible to environmental stress, mechanical damage while still on the vine such as wind rub, or damage during harvest. Thicker skins could also be an advantage during storage because they might reduce water loss. However, we have not yet studied skin anatomy in detail or determined whether thicker skins do in fact result in higher pack-out rates or less damage during storage. Thicker skins did not seem to retard fruit maturation.

Red-fleshed kiwifruit, especially selections of $A$. chinensis, are currently stimulating great interest among fruit breeders and the kiwifruit industry in general (Ferguson 
and Seal, 2008; Jiang et al., 2009). One of the most serious defects affecting commercial development of most red-fleshed selections available at present is their small fruit size (Cui, 1993). This might be overcome by chromosome doubling with colchicine (Wu et al., 2012). However, fruit of autotetraploid regenerants generally were less intensely colored and the distribution of pigments was more limited than in the diploid progenitors. The increase in fruit size after chromosome doubling is attributable mainly to the increase in fruit transverse diameters and this might affect both the concentration and distribution of anthocyanins. However, the distribution and intensity of red pigmentation varied in individual regenerants, suggesting that further selection could result in acceptably colored fruit.

Our results have showed that chromosome doubling significantly affected both fruit quality and fruit maturation in addition to fruit size and morphology. However, we have studied only some of the characters that determine fruit quality and whether a genotype produces fruit that meet commercial requirements. Core size and texture are also important as is the presence of any core cavities. Long storage life is another obvious requirement. However, the variation already observed in some important fruit quality characteristics among each group of autotetraploids indicates that there is a good chance of selecting desirable regenerants to be used as parents or directly as new commercial cultivars. Manipulation of ploidy certainly shows promise as a way of overcoming ploidy barriers in a genus such as Actinidia with species at different ploidy levels.

\section{Literature Cited}

Belrose, Inc. 2009. World kiwifruit review. 2009 Ed. Belrose, Inc. Publishers, Pullman, WA.

Burdon, J., D. McLeod, N. Lallu, J. Gamble, M. Petley, and A. Gunson. 2004. Consumer evaluation of 'Hayward' kiwifruit of different atharvest dry matter contents. Postharvest Biol. Technol. 34:245-255.

Campos, J.M.S., L.C. Davide, C.C. Salgado, F.C. Santos, P.N. Costa, P.S. Silva, C.C.S. Alves, L.F. Viccini, and A.V. Pereira. 2009. In vitro induction of hexaploid plants from triploid hybrids of Pennisetum purpureum and Pennisetum glaucum. Plant Breed. 128:101-104.

Cheng, C.H., A.G. Seal, S.J. Murphy, and R.G. Lowe. 2007. Red-fleshed kiwifruit (Actinidia chinensis) breeding in New Zealand. Acta Hort. 753:139-146.

Cheng, Z.-Q., W.-G. Liu, Z.-M. Liu, Z.-H. Yan, S.-J. Zhao, N. He, and J.-J. Zhang. 2008. Comparison of vitamin $\mathrm{C}$ contents in watermelon fruits with different ploidy. J. Fruit Sci. 25:760-763.
Cui, Z.-X. 1993. Zhongguo Mihoutao [Kiwifruit in China]. Shandong Science and Technology Publisher, Jinan, China.

Deutsch, M.J. 1996. Vitamins and other nutrients. 45.1.14. AOAC Official Method 967.21 Ascorbic acid in vitamin preparations and juices. 2,6-Dichloroindophenol titrimetric method. 45:16-17. In Cunniff, P. (ed.). Official methods of analysis of AOAC International. $16^{\text {th }} \mathrm{Ed}$. AOAC International, Gaithersburg, MD.

Feng, J., K.M. Maguire, and B.R. MacKay. 2003. Factors affecting ethylene production of Hayward kiwifruit. Acta Hort. 610:203-209.

Feng, J., A.V. McGlone, M. Currie, C.J. Clark, and B.R. Jordan. 2011. Assessment of yellowfleshed kiwifruit (Actinidia chinensis 'Hort16A') quality in pre- and post-harvest conditions using a portable near-infrared spectrometer. HortScience 46:57-63.

Ferguson, A.R. 2009. Kiwifruit cultivars, 2009. Italus Hortus 16(5):252-258.

Ferguson, A.R. and E.A. MacRae. 1992. Vitamin C in Actinidia. Acta Hort. 297:481-487.

Ferguson, A.R. and A.G. Seal. 2008. Kiwifruit, p. 235-264. In: Hancock, J.F. (ed.). Temperate fruit crop breeding: Germplasm to genomics. Springer, Dordrecht, The Netherlands.

Ferguson, A.R., J.-L. Zhang, A.M. Duffy, R.A. Beatson, C.-H. Cheng, P.M. Datson, R.G. Lowe, M.A. McNeilage, P.M. Harris-Virgin, A.G. Seal, and J.-H. Wu. 2009. Ploidia e uso della citometria a flusso nel miglioramento genetico dell'actinidia. Italus Hortus 16(5):78-83.

Harker, F.R., B.T. Carr, M. Lenjo, E.A. MacRae, W.V. Wismer, K.B. Marsh, M. Williams, A. White, C.M. Lund, S.B. Walker, F.A. Gunson, and R.B. Pereira. 2009. Consumer liking for kiwifruit flavour: A meta-analysis of five studies on fruit quality. Food Qual. Prefer. 20:30-41.

Hayward, M.D., N.O. Bosemark, and I. Romagosa. 1993. Plant breeding-Principles and prospects. Chapman \& Hall, Cambridge, UK.

Jaeger, S.R., R. Harker, C.M. Triggs, A. Gunson, R.L. Campbell, R. Jackman, and C. RequejoJackman. 2011. Determining consumer purchase intentions: The importance of dry matter size and price of kiwifruit. J. Food Sci. 76:S177-S184.

Jiang, Z., H. Huang, C. Zhong, Z. Zhang, and S. Wang. 2009. The development of the Chinese kiwifruit industry. Italus Hortus 16(5):245-251.

Li, S.X., Z.-J. Wu, Z.-G. Yang, and M.-Z. Li. 2002. The breeding of autotetraploid eggplant cultivar Xinqie No 1. Sci. Agr. Sin. 35:686-689.

Liu, Q.-Z., K.-J. Yuan, L.-S. Zhang, H.-J. Zhao, P. Liu, and Z.-H. Han. 2006. Growth and fruit characteristics of autotetraploid plants of Royal Gala apple. J. Fruit Sci. 23:102-104.

Luo, Y.-W., Z.-J. Qiao, Z.-Y. Zhu, Z.-S. Huangpu, and J.-H. Chang. 1997. Study on autotetraploid grape cv. Muscat Hamburg with good quality. Acta Hort. Sin. 24:125-127.

Martin, P. 2005. Spot the difference. New Zealand Kiwifruit J. 169:12-15.

McGhie, T.K. and G.D. Ainge. 2002. Color in fruit of the genus Actinidia: Carotenoid and chlorophyll compositions. J. Agr. Food Chem. 50:117-121

Meru, G. 2012. Polyploidy. In: Brummer, C. and C. McGregor (eds.). Plant breeding in the $21^{\text {st }}$ century. PBGG, University of Georgia, Athens, GA. 16 Jan. 2013.<http://projects.coe.uga.edu/ plantbreeding/index.php?title=Main_Page $>$.

Minchin, P.E.H., N. De Silva, W.P. Snelgar, A.C. Richardson, and T.G. Thorp. 2003. Modelling of colour development in the fruit of Actinidia chinensis 'Hort16A'. N. Z. J. Crop Hort. Sci. 31:41-53.

Monastra, F. and A. Testoni. 1992. Horticultural performance and quality characteristics of fruit from kiwifruit plants (cv. Hayward) obtained by in-vitro propagation, by cuttings and by grafting. Acta Hort. 297:197-203.

Montefiori, M., T.K. McGhie, I.C. Hallett, and G. Costa. 2009. Changes in pigments and plastid ultrastructure during ripening of green-fleshed and yellow-fleshed kiwifruit. Sci. Hort. 119:377387.

Nukaya, T., M. Yahata, K. Suzuki, K. Yasuda, H. Kunitake, H. Komatsu, H. Mukai, H. Harada, and T. Takagi. 2009. Fruit characteristics in autotetraploid Meiwa kumquat induced by colchicine treatment to nucellar embryos. Hort Environ. Biotechnol. 50:188-190.

SAS Institute Inc. 2000-04. SAS 9.1.3 help and documentation. SAS Institute Inc. Cary, NC.

Sugiyama, S.I. 2005. Polyploidy and cellular mechanisms changing leaf size: Comparison of diploid and autotetraploid populations in two species of Lolium. Ann. Bot. (Lond.) 96:931938.

Van Laere, K., S.C. Franca, H. Vansteenkiste, J. Van Huylenbroeck, K. Steppe, and M.-C. Van Labeke. 2011. Influence of ploidy level on morphology, growth and drought susceptibility in Spathiphyllum wallisii. Acta Physiol. Plant 33:1149-1156.

Viehmannová, I., M. Trávíčková, E. Špatenková, M. Cerná, and P. Trávníček. 2012. Induced polyploidization and its influence on yield, morphological, and qualitative characteristics of microtubers in Ullucus tuberosus. Plant Cell Tissue Organ Cult. 109:83-90.

Woodward, T.J. and M.J. Clearwater. 2008. Relationships between 'Hayward' kiwifruit weight and dry matter content. Postharvest Biol. Technol. 48:378-382.

Wu, J.-H., A.R. Ferguson, and B.G. Murray. 2011 Manipulation of ploidy for kiwifruit breeding: In vitro chromosome doubling in diploid Actinidia chinensis Planch. Plant Cell Tissue Organ Cult. 106:503-511.

Wu, J.-H., A.R. Ferguson, B.G. Murray, Y. Jia, P.M. Datson, and J. Zhang. 2012. Induced polyploidy dramatically increases the size and alters the shape of fruit in Actinidia chinensis. Ann. Bot. (Lond.) 109:169-179.

Ye, Y.M., J. Tong, X.P. Shi, W. Yuan, and G.R. Li. 2010. Morphological and cytological studies of diploid and colchicine-induced tetraploid lines of crape myrtle (Lagerstroemia indica L.). Sci. Hort. 124:95-101. 